\title{
Strategi Pemberdayaan Masyarakat dalam Pengembangan Jiwa Kewirausahaan (Entrepreneurship) di Dusun Langkan, Desa Landih, Kecamatan Bangli, Kabupaten Bangli
}

\author{
I WAYAN SUI SUADNYANA, \\ I GEDE SETIAWAN ADI PUTRA,I MADE SARJANA
}

\author{
Program Studi Agribisnis, Fakultas Pertanian, Universitas Udayana \\ Jalan PB. Sudirman 80232 Denpasar, Bali \\ E-mail:sui.suadnyana19031995@gmail.com \\ igedesetiawanadiputra@gmail.com
}

\begin{abstract}
Community Empowerment Strategy in Entrepreneurship Spirit Development in Langkan Sub-Village, Landih Village, Bangli District, Bangli Regency
\end{abstract}

Community empowerment as a development concept fulfills social values. One of the efforts is through entrepreneurship development. The community of Langkan Sub-Village, Landih Village, Bangli District, Bangli Regency is a potential area to be empowered in the field of entrepreneurship. Therefore, this study aims to identify internal factors in the form of strengths and weaknesses as well as external factors in the form of opportunities and threats. After getting these factors, then the strategy of community empowerment was formulated in the development of entrepreneurship spirit. These factors were analyzed using IFASEFAS analysis, SWOT quadrant analysis, IE matrix, and SWOT matrix. The results showed that the main strength in Langkan Sub-Village is in the form of available agricultural land adequate for the development of entrepreneurship. The main weakness is that there was no association, group or similar business organization causing the lack of coordination. The main opportunity is that there were increasingly serious efforts of the government to increase the number of entrepreneurs both in agriculture and non-agriculture sectors. While the main threat is the flow of world trade that causes losses if they are not able to compete. Through the SWOT analysis quadrant, it can be seen that the community was on a progressive strategy. While the I-E Matrix formula finds the strategy of harvest and divestment. In addition, SWOT matrix analysis found 14 alternative strategies. The most priority strategy is to encourage human resources who are educated, have the skills, have the spirit and the willingness to go forward to follow the competition and the improvement of the entrepreneurial program so that there is an increase of entrepreneurial competence.

Keywords: Strategy, Community Empowerment, Entrepreneurship Development, SWOT Analysis 


\section{Pendahuluan}

\subsection{Latar Belakang}

Pemberdayaan masyarakat sebagai sebuah konsep pembangunan ekonomi yang merangkum nilai-nilai sosial. Konsep ini mencerminkan paradigma baru pembangunan, yakni bersifat people centered, participatory, empowering, and sustainable (Chambers, 1985 dalam Sumodiningrat dan Wulandari, 2016). Oleh karena itu pemberdayaan masyarakat selalu menekankan pada partisipasi masyarakat dalam setiap prosesnya, mulai dari perencanan sampai pada tahap evaluasi. Banyak sekali upaya yang dapat dilakukan dalam peningkatan kemandirian masyarakat, salah satunya dengan mengembangkan kewirausahaan atau entrepreneurship.

Masyarakat Dusun Langkan, Desa Landih, Kecamatan Bangli, Kabupaten Bangli sangat tepat diberdayakan dalam bidang kewirausahaan. Secara topologi lokasi Dusun Langkan berada di daerah pegunungan sehingga memiliki potensi besar dalam bidang pertanian sehingga sebagian besar masyarakatnya menekuni bidang tersebut. Terdapat juga masyarakat yang menekuni bidang kewirausahaan, bahkan telah ada yang mencoba usaha di bidang agribisnis. Tercetusnya usahausaha di bidang agribisnis tentu sejalan dengan keberadaaan potensi Dusun Langkan yang berada di sektor pertanian. Hal ini bisa dijadikan alternatif bagi masyarakat yang bekerja di sektor pertanian agar dapat terpacu menjadi wirausaha dengan memanfaatkan potensi pertanian yang ada.Agar dapat mendorong masyarakat menjadi wirausaha tentu diperlukan sebuah upaya. Pemberdayaan masyarakat di bidang kewirausahaan menjadi salah satu solusi guna mendorong hal tersebut. Mendorong jiwa kewirausahaan bukanlah hal yang mudah, dibutuhkan strategi-strategi khusus sehingga nantinya mampu terwujud. Oleh karena itu penting sekali dilakukan penelitian di Dusun Langkan, Desa Landih, Kecamatan Bangli, Kabupaten Bangli mengenai strategi yang digunakan dalam pengembangan jiwa kewirausahaan.

\subsection{Rumusan Masalah}

Berdasarkan latar belakang di atas, adapun rumusan masalah yang dapat diambil diantaranya.

1. Apasaja kekuatan, kelemahan, peluang, dan ancaman masyarakat dalam pengembangan jiwa kewirausahaan di Dusun Langkan, Desa Landih, Kecamatan Bangli, Kabupaten Bangli?

2. Bagaimana strategi pengembangan jiwa kewirausahaan di Dusun Langkan, Desa Landih, Kecamatan Bangli, Kabupaten Bangli?

\subsection{Tujuan Penelitian}

Adapun tujuan penelitian ini sebagai berikut.

1. Mengetahui kekuatan, kelemahan, peluang, dan ancaman masyarakat dalam pengembangan jiwa kewirausahaan di Dusun Langkan, Desa Landih, Kecamatan Bangli, Kabupaten Bangli.

2. Menganalisis strategi pengembangan kewirausahaan di Dusun Langkan, Desa Landih, Kecamatan Bangli, Kabupaten Bangli. 


\section{Metodologi Penelitian}

\subsection{Lokasi dan Waktu Penelitian}

Penelitian ini dilaksanakan di Dusun Langkan, Desa Landih, Kecamatan Bangli, Kabupaten Bangli. Penentuan lokasi penelitian dilaksanakan secara purposive yaitu pemilihan lokasi yang dilaksanakan secara sengaja. Penelitian ini dilaksanakan pada bulan Juli hingga Agustus 2017.

\subsection{Jenis dan Sumber Data}

Jenis data yang digunakan dalam penelitian ini berupa kualitatif dan kuantitatif. Data kualitatif adalah data yang berwujud uraian terinci, kutipan langsung, dan dokumentasi kasus (Sitorus, 1998 dalam Agusta, 2012). Data kualitatif dalam penelitian ini nantinya berupa jawaban-jawaban ataupun pendapat dari informan serta dokumentasi dan hasil observasi dari lapangan. Data kuantitatif adalah data yang dinyatakan dalam bentuk angka (Santoso, 2010). Data kuantitatif dalam penelitian ini diantaranya data luas wilayah, jumlah penduduk serta data lainnya yang terkait dan dapat menunjang penelitian.Sumber data yang digunakan dalam penelitian ini yakni data primer dan data sekunder. Data primer adalah data yang langsung didapat dari lapangan, sedangkan data sekunder yakni data yang didapatkan dari sumber lain seperti BPS, buku-buku, internet serta sumber lainnya yang mendukung penelitian.

\subsection{Metode Pengumpulan Data}

Metode penelitian yang digunakan dalam penelitian ini menggunakan metode wawancara. Wawancara adalah pertemuan dua orang untuk bertukar informasi dan ide melalui tanya jawab sehingga dapat dikontruksikan makna dalam suatu teknik tertentu (Sugiyono, 2007 dalam Prastowo, 2014). Wawancara yang digunakan dalam penelitian ini yakni berupa wawancara terstruktur dan wawancara mendalam (in-depth interview).

\subsection{Populasi dan Sampel}

Populasi adalah keseluruhan objek yang akan/ingin diteliti. Populasi ini sering juga disebut universe. Anggota populasi dapat berupa benda hidup maupun benda mati, dimana sifat-sifat yang ada padanya dapat diukur atau diamati. Populasi dalam penelitian ini yakni masyarakat Dusun Langkan, Desa Landih, Kecamatan Bangli, Kabupaten Bangli yang berusia produktif (umur 15-64 tahun) berjumlah 359 orang.Sampel adalah bagian dari populasi yang menjadi objek penelitian (Nasution, 2013).Penentuan sampel menggunakan rumus Slovindidapatkan sebanyak 78,2 dan dibulatkan menjadi 79 orang.Sedangkan teknik sampling yang digunakan berupa incidental sampling.

\subsection{Penentuan Informan Kunci}

Informan kunci dalam penelitian ini untuk pertama kali dipilih secara purposive yakni secara sengaja dengan pertimbangan tertentu. Informan kunci tersebut yakni Kepala Dusun Langkan I Nengah Beratha. Kepala Dusun dipilih karena dianggap mengetahui tentang berbagai situasi dan kondisi Dusun Langkan serta seluruh pemangku kepentingan yang terlibat di dalamnya. Pemilihan informan kunci berikutnya dipilih menggunakan snowball sampling. 


\subsection{Instrumen Penelitian}

Instrumen penelitian merupakan alat yang dipakai dalam sebuah penelitian. Sugiyono (2016) mengatakan instrumen penelitian adalah suatu alat yang digunakan untuk mengukur fenomena alam atau sosial yang diamati. Penelitian ini menggunakan intrumen berupa kuesioner dan pedoman wawancara. Kuesioner ditujukan kepada seluruh responden sedangkan pedoman wawancara ditujukan kepada informan kunci penelitian.

\subsection{Pengujian Instrumen Penelitian}

Pengujian variabel penelitian dalam kuisioner dilakukan dengan uji validitas dan reabilitas. Azwar (1987) dalam Matondang (2009) menyatakan bahwa validitas berasal dari kata validity yang berarti sejauhmana ketepatan dan kecermatan suatu instrumen dalam melakukan fungsi ukurnya. Sedangkan reabilitas (raliablelity) menurut Sugiarto dan Simanjuntak (2006) dikutip dalam binus.ac.id menyatakan bahwa instrumen yang digunakan sebagai alat pengumpulan data mampu mengungkapkan informasi yang sebenarnya di lapangan.Pengujian validitas dan reabilitas dilakukan dengan menggunakan software SPSS.

\subsection{Metode Analisis Data}

Analisis data yang digunakan dalam penelitian ini menggunakan SWOT. Menurut BPS, analisis SWOT adalah analisis kondisi internal maupun eksternal suatu organisasi/masyarakat yang selanjutnya akan digunakan sebagai dasar untuk merancang strategi dan program kerja. Analisis internal meliputi penilaian terhadap faktor kekuatan (strength) dan kelemahan (weakness). Analisis eksternal mencakup faktor peluang (oppourtunity),dan tantangan (threaths). Analisis SWOT ini terbagi atas analisis kualitatif dan kuantitatif.

Pendekatan kualitatif matriks SWOT menampilkan delapan kotak, yaitu dua paling atas adalah kotak faktor eksternal (peluang dan tantangan) sedangkan dua kotak sebelah kiri adalah faktor internal (kekuatan dan kelemahan). Empat kotak lainnya merupakan kotak isu-isu strategis yang timbul sebagai hasil titik pertemuan antara faktor-faktor internal dan eksternal. Analisis kuantitatif SWOT berupa analisis IFAS dan EFAS dan Matriks Internal-Eksternal (IE) Analisis SWOT.

\section{a. Analisis IFAS dan EFAS}

Data SWOT kualitatif di atas dapat dikembangkan secara kuantitatif melalui perhitungan Analisis SWOT yang dikembangkan oleh Pearce dan Robinson (1998)dalam BPS (n.d) agar diketahui secara pasti posisi organisasi yang sesungguhnya. Apabila sudah dihitung mengenai faktor IFAS dan EFAS melalui tabel diatas maka selanjutnya dapat ditentukan strategi melalui kuadran analisis SWOT dibawah ini.

\section{b. Matriks Internal-Eksternal (IE) Analisis SWOT}

Menurut Setyorini (2016) matriks ini bermanfaat untuk memposisikan analisis ke dalam matriks yang terdiri dari 9 sel. Matriks IE terdiri dari dua dimensi, yaitu total skor matriks IFE pada sumbu X dan Matriks EFE pada sumbu Y. Matriks ini dikelompokkan menjadi tiga strategi utama yaitu: 
1. Grow and Build (Tumbuh dan Bina) berada dalam sel I, II atau IV. Strategi yang cocok adalah intensif (penetrasi pasar, pengembangan pasar, dan pengembangan produk) atau integrasi (integrasi ke belakang, integrasi ke depan, dan integrasi horizontal).

2. Hold and Maintain (Pertahankan dan Pelihara) mencangkup sel III, V, atau sel VII. Strategi umum yang dipakai adalah penetrasi pasar, pengembangan produk dan pengembangan pasar.

3. Harvest and Devest (Panen atau Divestasi) mencangkup sel VI, VIII, atau IX. Strategi yang dipakai adalah divestasi strategi diversifikasi konglomerat, dan strategi likuidasi.

\section{c. Hasil dan Pembahasan}

\subsection{Identifikasi Faktor Internal dan Eksternal \\ 3.1.1 Identifikasi faktor internal}

\section{Faktor Kekuatan}

Berdasarkan hasil identifikasi dapat dikelompokkan faktor-faktor kekuatan sebagai seperti, (a) di Dusun Langkan tersedia lahan pertanian yang memadai untuk pengembangan wirausaha, (b) masyarakat Dusun Langkan menanam berbagai jenis varietas tanaman dalam kegiatan usaha tani, (c) di wilayah Dusun Langkan terdapat sumber mata air yang dapat dijadikan sarana pendukung kegiatan usaha pertanian, (d) masyarakat Dusun Langkan mudah untuk mendapatkan sarana dan prasarana pertanian seperti pupuk, benih, bibit, dan lain sebagainya, (e) kawasan Dusun Langkan dekat dengan daerah wisata seperti Objek Wisata Penelokan, Objek Wisata Pura Ulun Danu Batur, dan Objek Wisata Desa Pengotan sehingga berpeluang dibangunnya usaha-usaha baru, (f) di Dusun Langkan telah tumbuh beberapa wirausaha, baik dari bidang pertanian maupun non pertanian, (g) masyarakat Dusun Langkan mengetahui jenis komoditas yang akan mendatangkan keuntungan lebih tinggi, (h) masyarakat Dusun Langkan secara teknis mampu mengelola usaha dengan baik sehingga menghasilkan produk dengan kualitas tinggi, (i) masyarakat Dusun Langkan mempunyai kemampuan yang cepat dalam menganalisa jenis usaha baru yang memiliki prospek bagus untuk dikembangkan, (j) di Dusun Langkan pernah diadakan penyuluhan atau pelatihan untuk peningkatan keterampilan petani, $(\mathrm{k})$ masyarakat di Dusun Langkan rata-rata pernah bersekolah, baik secara formal (SD, SMP, SMA, Perguruan Tinggi) dan informal (kursus, pelatihan, kejar paket dan lain sebagainya), (1) masyarakat dusun Langkan memiliki semangat belajar dengan mencontoh keberhasilan orang lain, (m) masyarakat Dusun Langkan memiliki keinginan yang kuat untuk meraih kemajuan, (n) masyarakat Dusun Langkan selalu kritis terhadap berbagai persoalan, (o) generasi muda di Dusun Langkan yang berumur sekitar 20-40 tahun memiliki semangat untuk berwirausaha terbukti dengan adanya usaha bengkel, show room, usaha pertanian dan lain sebagainya, (p) hampir tidak ada generasi muda di Dusun Langkan yang menjadi PNS, tetapi lebih banyak yang langsung terjun mengelola usaha keluarga atau kelompok, (q) masyarakat Dusun Langkan memiliki tanggungjawab yang kuat dalam mengelola usaha atau pekerjaannya, dan (r) masyarakat Dusun Langkan rata-rata taat terhadap aturan lembaga keuangan (bank, LPD, koperasi) sehingga mendapat kepercayaan meminjam modal usaha. 


\section{Faktor Kelemahan}

Berdasarkan hasil identifikasi ditemukan faktor-faktor kelemahan seperti, (a) masyarakat Dusun Langkan rata-rata belum mampu mengelola keuangan usahanya dengan baik, (b) adanya masyarakat Dusun Langkan yang mempunyai pandangan bahwa pengusaha lebih rendah dari pegawai, (c) ada beberapa masyarakat di Dusun Langkan yang menganggap bahwa pendidikan sebagai hal yang kurang penting, (d) masyarakat Dusun Langkan banyak yang belum mengikuti kursus/pelatihan singkat terkait pengembangan kemampuan mengelola usaha, (e) lemahnya posisi tawar masyarakat Dusun Langkan dalam penjualan produk pertanian, (f) masyarakat Dusun Langkan sering merasa kesulitan dalam mengakses modal untuk kegiatan berwirausaha, (g) berbagai usaha sejenis di Dusun Langkan sering terjadi perang harga, dan (h) belum ada asosiasi, peguyuban, atau organisasi usaha sejenis sehingga menyebabkan minimnya koordinasi.

\subsubsection{Identifikasi faktor eksternal}

\section{Faktor Peluang}

Faktor peluang (oppourtunity) yakni faktor-faktor yang dapat diraih sebagai bagian dalam mendukung peningkatan jiwa kewirausahaan di Dusun Langkan. Faktor ancaman ini juga telah dibagi kedalam dua kategori yakni dilihat dari kependudukan dan juga dari segi pembangunan. Faktor-faktor tersebut dijabarkan diantaranya, (a) meningkatnya jumlah penduduk Bali dan Indonesia pada umumnya menuntut ketersediaan barang dan jasa yang lebih beragam, (b) adanya kompetisi wirausaha yang diselenggarakan oleh lembaga terkait, seperti Dinas Pendidikan, Pemuda dan Olahraga; Bank Indonesia; Kementerian Koperasi dan lain sebagainya, (c) adanya upaya pemerintah yang semakin serius dalam peningkatan jumlah wirausaha baik di bidang pertanian maupun non-pertanian, (d) adanya upaya pemerintah menciptakan iklim kewirausahaan yang lebih transparan dan berkelanjutan dimana semua orang mempunyai kesempatan yang sama untuk menjadi wirausaha, (e) adanya upaya pemerintah yang menggalakan pemerataan pembangunan baik dari segi perekonomian dan pembangunan infrastruktur seperti jembatan, jalan, pelabuhan, dan lain sebagainya.

\section{Faktor Ancaman}

Faktor ancaman (treath) merupakan faktor yang berasal dari luar masyarakat yang tidak mampu mendukung bahkan merugikan bagi pengembangan jiwa kewirausahaan di Dusun Langkan, Desa Landih, Kecamatan Bangli, Kabupaten Banglimaka didapatkan faktor-faktor ancaman tersebut diantaranya, (a) adanya pedagang pengepul yang mempermainkan harga produk pertanian sehingga dapat merugikan petani, (b) adanya produk impor masuk ke Indonesia yang menyebabkan turunnya nilai produk dalam negeri sehingga dapat merugikan para pengusaha di dalam negeri, dan (c) adanya arus perdagangan dunia yang menyebabkan kerugian apabila tidak mampu bersaing.

Berdasarkan pembahasan faktor kekuatan, kelemahan, peluang dan ancaman diatas dapat ditemukan nilai IFAS dan EFAS untuk menentukan strategi pemberdayaan masyarakat dalam pengembangan jiwa kewirausahaan di Dusun Langkan, Desa Landih, Kecamatan Bangli, Kabupaten Bangli. Maka dari itu dapat 
ditentukan strategi tersebut melalui kuadran analisis SWOT. Adapun nilai IFAS yakni sebesar 2,905 sedangkan nilai EFAS sebesar 1,874. Berdasarkan diagram kartesius analisis SWOT dapat dilihat pada gambar berikut.

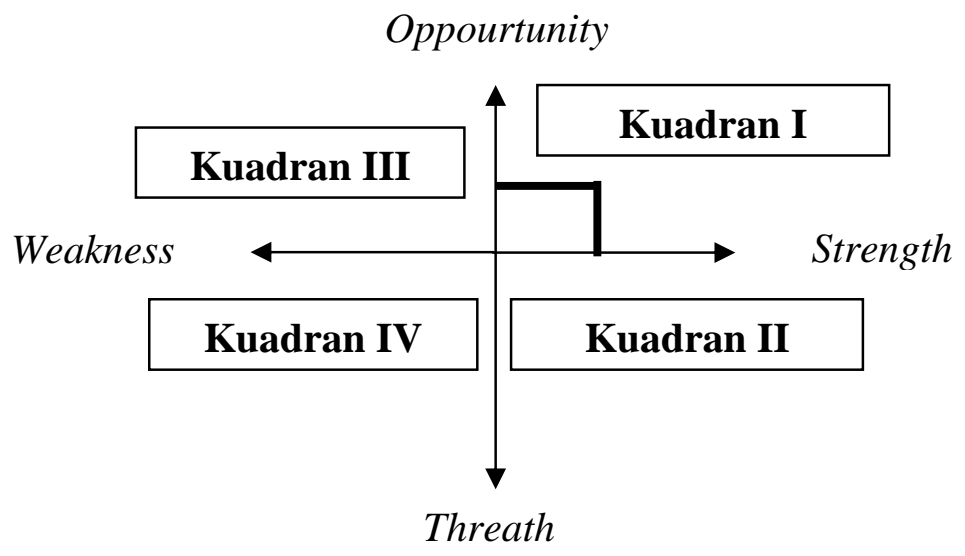

Gambar 1. Hasil Kuadran Analisis Strategi Pemberdayaan Masyarakat dalam Pengembangan Jiwa Kewirausahaan di Dusun Langkan, Desa Landih, Kecamatan Bangli, Kabupaten Bangli

Berdasarkan kuadran tersebut maka dapat diketahui bahwa Dusun Langkan berada di kuadran I (positif,positif). Kuadran ini menandakan bahwa strategi berupa progresif yang artinya masyarakat kuat dan berpeluang. Oleh karena itu masyarakat siap untuk berkembang kearah yang lebih baik untuk melakukan sebuah pemberdayaan masyarakat dalam pengembangan jiwa kewirausahaan.

\subsection{Matriks Internal dan Eksternal (IE)}

Melalui penentuan matriks IFAS dan EFAS juga dapat ditentukan strategi dengan matriks Internal dan Ekesternal. Adapun nilai IFAS yakni sebesar 2,905 sedangkan nilai EFAS sebesar 1,874. Rumusan matriks IE didapatkan sebagai berikut.

\section{Total Nilai Faktor Internal}

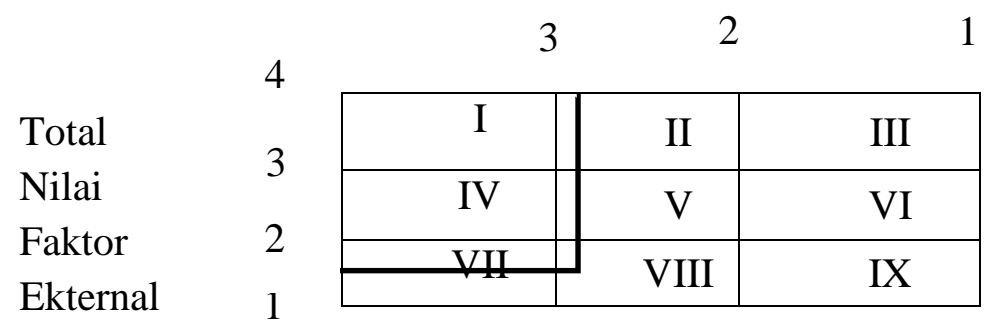

Gambar 2Matriks Internal-Eksternal (IE) Strategi Pemberdayaan Masyarakat dalam Pengembangan Jiwa Kewirausahaan di Dusun Langkan, Desa Landih, Kecamatan Bangli, Kabupaten Bangli

Berdasarkan Gambar 2 dapat diketahui bahwa kawasan Dusun Langkan, Desa Landih, Kecamatan Bangli, Kabupaten Bangli berada di sel VIII yaitu 3 Harvest and Devest (Panen atau Divestasi). 


\subsection{Strategi Alternatif Pengembangan Jiwa Kewirausahaan}

Strategi Alternatif dalam pengembangan jiwa kewirausahaan dianalisis menggunakan matriks kualitatif SWOT yang disusun seperti gambar 3.

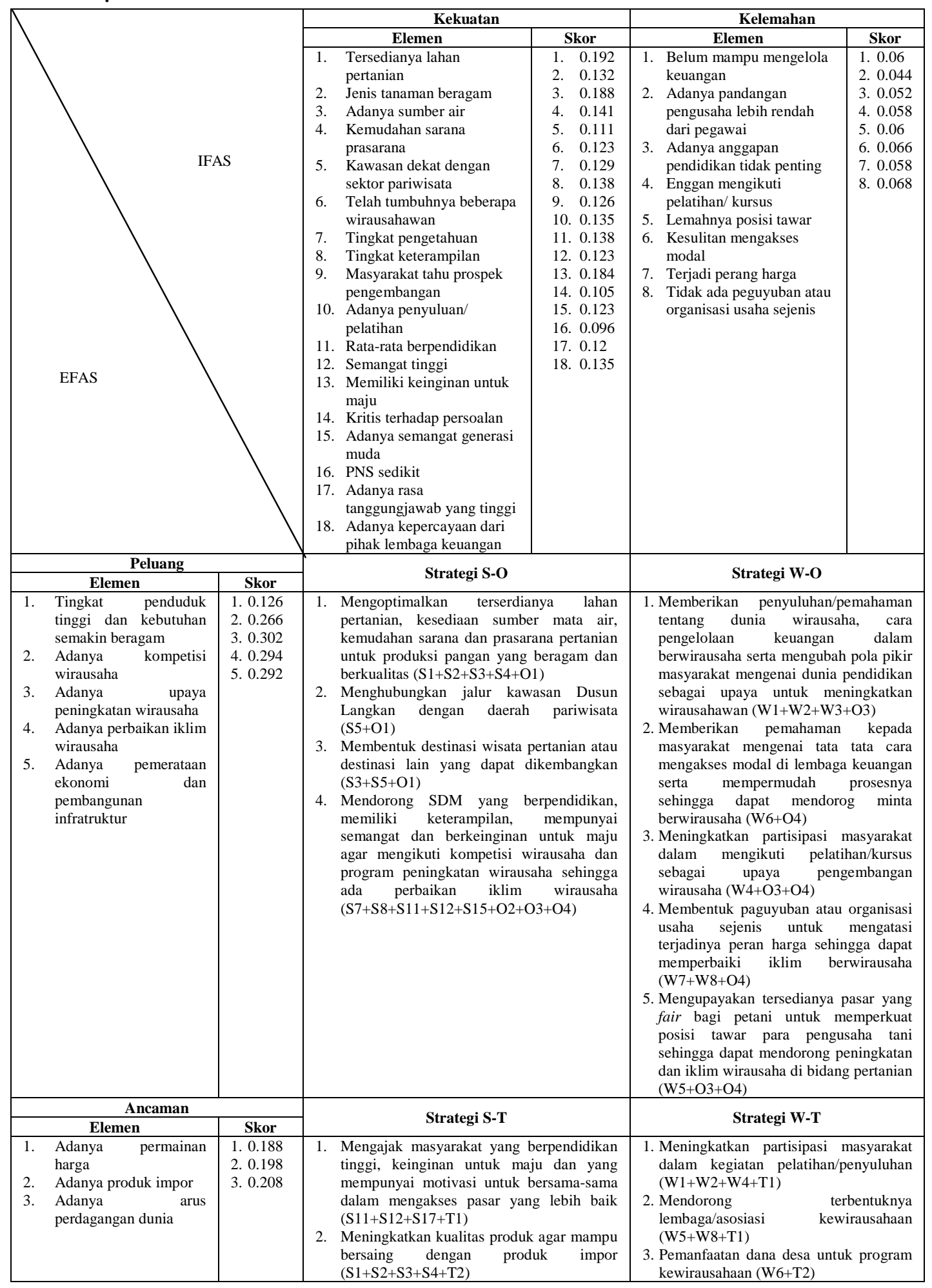

Gambar 3Analisis Alternatif Strategi Pemberdayaan Masyarakat dalam Pengembangan Jiwa Kewirausahaan di Dusun Langkan, Desa Landih, Kecamatan Bangli, Kabupaten Bangli 
Berbagai rumusan strategi alternatif tersebut, selanjutnya harus dipilih strategi prioritas. Pemilihan strategi prioritas dimaksudkan untuk mengetahui strategi yang paling penting untuk diterapkan. Pemilihan strategi prioritas dilakukan dengan cara menjumlahkan skor masing-masing elemen yang berpengaruh dalam menciptakan strategi yang bersangkutan. Dari hasil pernjumlahan tersebut maka didapatkan skor masing-masing strategi lalu diurutkan dari skor yang paling besar ke paling kecil. Strategi dengan skor paling besar tentu langsung menjadi strategi prioritas, sedangkan strategi dengan skor paling kecil bersifat sebaliknya.

Strategi paling prioritas yakni mendorong SDM yang berpendidikan, memiliki keterampilan, mempunyai semangat dan keinginan untuk maju agar mengikuti kompetisi wirausaha dan program peningkatan wirausaha sehingga ada perbaikan iklim wirasaha. Terpilihnya strategi tersebut menjadi prioritas dikarenakan skor yang diperoleh paling tinggi diantara strategi laiinya. Skor yang paling tinggi disebabkan oleh banyaknya elemen yang mendukung terciptanya strategi tersebut.

Kedepan strategi ini harus dioptimalkan, mengingat di Dusun Langkan memang tersedia SDM yang memiliki kompetensi. Upaya pengembangan wirausaha memang dibutuhkan sumber daya manusia yang mumpuni di dalamnya. Salah satu cara untuk melihat hal tersebut yakni melalui proses pendidikan yang pernah dilalui oleh SDM itu sendiri, selain itu memang dibutukan semangat dari SDM yang bersangkutan serta memang memiliki motivasi dan keinginan yang kuat untuk meraih kemajuan. Tanpa hal tersebut pembangunan jiwa kewirausahaan akan terasa sulit.

\section{Penutup}

\subsection{Kesimpulan}

Berdasarkan hasil penelitian dan pembahasan dapat ditarik kesimpulan sebagai berikut.

1. Terdapat 18 faktor kekuatan, delapan faktor kelemahan, lima faktor peluang dan tiga faktor ancaman masyarakat Dusun Langkan dalam pengembangan jiwa kewirausahaan. Faktor kekuatan yang paling utama yakni di Dusun Langkan memiliki lahan pertanian yang sangat memadai untuk pengembangan wirausaha dibidang pertanian. Faktor kelemahan utama berupa belum adanya asosiasi, paguyuban atau organisasi usaha sejenis. Faktor peluang utama berupa adanya upaya pemerintah yang semakin serius dalam meningkatkan jumlah wirausaha, baik di bidang pertanian maupun non-pertanian. Terakhir, ancaman utamanya adalah adanya arus perdagangan dunia yang menyebabkan kerugian apabila masyarakat tidak mampu bersaing.

2. Strategi masyarakat Dusun Langkan berupa strategi progresif yang artinya masyarakat kuat dan berpeluang untuk pengembangan jiwa kewirausahaan. Selain itu ditemukan strategi panen dan divestasi serta didapatkan 14 strategi alternatif. Terdapat satu strategi yang paling prioritas yaitu mendorong SDM yang berpotensi (berpendidikan, terampil, antusias dan ingin maju) agar mengikuti kompetisi wirausaha dan program peningkatan wirausaha sehingga ada perbaikan iklim wirausaha agar tercipta calon-calon pengusaha bidang pertanian di Dusun Langkan. 


\subsection{Saran}

Berdasarkan hasil penelitian, adapun saran yang dapat diberikan diantaranya.

1. Di dalam upaya pengembangan jiwa kewirausahaan maka harus mengajak masyarakat yang mempunyai kompetensi yang memiliki pengalaman pendidikan dan keterampilan serta mempunyai motivasi untuk maju sesuai dengan strategi yang paling prioritas. Hal ini dimaksudkan untuk membangun geliat wirausaha agar kedepan bisa berjalan dengan baik sesuai dengan perencanaan. Selain itu bersama masyarakat yang telah berpengalaman dan berpendidikan tersebut dapat mengupayakan mengatasi kelemahan seperti membentu pasar yang fair bagi masyarakat yang menekuni usaha tani.

2. Pemimpin (kepala dusun) bersama stakeholder terkait harus mendorong masyarakat Dusun Langkan berwirausaha di bidang pertanian. Hal ini karena potensi Dusun Langkan berada di bidang pertanian yang juga didukung dengan adanya sumber mata air dan kemudahan dalam mengakses sarana dan prasarana pertanian.

\section{Daftar Pustaka}

Agusta, Ivanovich. 2012. Teknik Pengumpulan dan Analisis Data Kualitatifdalam http://www.academia.edu/download/34265413/ivan-pengumpulan-analisisdata-kualitatif.pdf diakses 10 Maret 2017

Badan Pusat Statistik. n.d. ANALISIS SWOT dalam daps.bps.go.id/file_artikel/66/Analisis\%20SWOT.pdf diakses 22 Maret 2017

Prastowo, Andi. 2014. Metode Penelitian Kualitatif dalam Rancangan Perspektif Penelitian. Yogyakarta: Ar-Ruzz Media

Santoso, Singgih. 2010. Statistik Parametrik: Konsep dan Aplikasi dengan SPSS. PT. Elex Media Komputindo: Jakarta

Setyorini, Hany. 2016. Analisis Strategi Pemasaran Menggunakan Matriks SWOT dan QSPM: Studi Kasus: Restoran WS Soekarno Hatta Malang. Department of Agro-industrial Technology, Faculty of Agricultural Technology University of Brawijaya: Malang dalam http://industria.ub.ac.id/index.php/industri/article/download/269/261 diakses tanggal 9 September 2017

Sugiyono. 2016. Metode Penelitan Kuantitatif, Kualitatif, dan R\&D. Penerbit Alfabeta: Bandung

Sumodiningrat, Gunawan dan Ari Wulandari. 2016. Membangun Indonesia dari Desa: Pemberdayaan Desa sebagai Kunci Kesuksesan Pembangunan Ekonomi untuk Meningkatkan Kesejahteraan Masyarakat. Media Pressindo: Yogyakarta

Nasution, Rozaini. 2013. Teknik Sampling dalam library.usu.ac.id/download/fkm/fkm-rozaini.pd diakses 19 Maret 2017

Matondang, Zulkifli. 2009. Validitas dan Reabilitas Suatu Intstrumen Penelitian dalam http://digilib.unimed.ac.id/705/1/validitas-dan-reabilitas-suatu-instrumenpenelitian.pdf diakses 12 Juli 2017

Binus University. 2014. Uji Validitas dan Reabilitas dalam qms.binus.ac.id/u-j-iv-a-l-i-d-i-t-a-s-d-a-n-r-e-a-b-i-l-i-t-a-s/ diakses diakses 12 Juli 2017 